\title{
Examining the Self-Perceived Development of Cultural Intelligence (CQ) in a Blended Learning Environment
}

\author{
Peter W. Roux***, Ryuichi Matsuba**, Yoshiko Goda** and Katsuaki Suzuki**
}

(Received 12 December 2018 and accepted in revised form 14 June 2019)

\begin{abstract}
This paper examines the self-perceived development of cultural intelligence (CQ) as expressed by Japanese university students taking courses on intercultural learning. An earlier developed instructional framework was employed to support course design and development, which is adapted in the current application for use in a blended-learning format. The development of CQ is explored through a qualitative analysis of data obtained in a series of reflection-based online surveys specifically designed to trace learning response patterns. The results show an array of learning responses that could be thematically organized and qualitatively linked to the development of CQ. We draw connections to the CQ concept via students' self-reported advances in cultural knowledge, skills and strategies, as well as changes in attitudes and beliefs. Course effectiveness and learning engagement are discussed with implications for the design of a learning management system that supports the growth of CQ and the formation of a global mindset.
\end{abstract}

Keywords: blended learning, cultural intelligence (CQ), instructional design, global mindset, Japanese higher education

\section{Introduction}

The effects of globalization continue to extend its reach, exerting various pressures on the internationalization of higher education ${ }^{(1-3)}$. These forces were previously noticeable particularly in the proliferation of socalled 'outbound programs': foreign study-abroad, exchange and immersion programs ${ }^{(1)}$. In Japan, it has also recently become recognizable in the increasing numbers of an 'inbound' student cohort ${ }^{(4)}$. Internationalization programs typically include two streams of activities: one type that includes internationalization activities which occur on the home/local campus, and the other type which refers to activities that happen abroad or across borders ${ }^{(2)}$.

Since 2010, Japanese universities have been formally tasked by the Ministry of Education, Culture, Sports, Science \& Technology $(\mathrm{MEXT})^{(5)}$ to increase efforts to internationalize higher education. Although outbound programs continue to be maintained, Japanese universities are also increasingly accommodating inbound, or foreign students, on local campuses. This latter trend is having a diversifying effect on the student populations of Japan's formerly largely mono-cultural university campuses ${ }^{(4)}$. Although a few universities have embraced this trend fully, the true benefits of this development for the larger Japanese society remains yet to be

\footnotetext{
*Saga University, Japan

**Graduate School of Instructional Systems (GSIS), Kumamoto University, Japan
}

seen.

Research suggests that some of the purported benefits of cosmopolitan campuses are that students gain educationally from the interaction and social learning that accompanies studying alongside international counterparts ${ }^{(1-4)}$. Aside from the international networking that occurs during cross-cultural experiences, the process of learning to communicate inter-culturally enables students to gain and develop a set of soft skills that have become sought after in the global business and social environment ${ }^{(6)}$.

As part of a broader project that explores the design of an instructional system to support intercultural skill —or cultural intelligence (CQ) - development ${ }^{(7-13)}$, the current investigation presents a limited set of results that showcases the self-reported CQ gains made by a group of mostly Japanese university students. Earlier reports ${ }^{(11,12)}$ confirmed the efficacy of a framework we developed to explore and support intercultural skills development, while later research work presented findings that measured CQ development ${ }^{(8-10,13)}$.

For our current purpose, we focus primarily on the qualitative gains in CQ, obtained through students' selfreported advances in cultural knowledge, skills and strategies, and discuss changes in participants' attitudes and beliefs. We further highlight course design and learning engagement with reference to implications for the design of a learning management system that supports the growth of CQ and the formation of a global mindset in Japanese higher education. 


\section{Fostering a Global Mindset Through Developing Cultural Intelligence (CQ)}

Broadly speaking, a person with a global mindset can be described as having a general predisposition, displays tolerance for other peoples and cultures, considers cultural diversity an asset and is able to thrive within ambiguity. Such an individual can balance and utilize seemingly contradictory forces and is able to reconceptualize boundaries ${ }^{(6,14)}$. Giving consideration to the digital and educational requirements of the current age, global management researchers ${ }^{(15)}$ suggest a model of knowledge and skill that connects three overlapping bases to describe a global mindset. In summary, researchers in this area ${ }^{(6)}$ suggest that managers should have: “... (1) a degree of mastery over technology, information systems and telecommunications; (2) an understanding of the socio-political factors of the different countries in which an organization operates; and (3) an appreciation of the role of culture and cross-cultural issues that impact management's decisions (p. 276)."

In previous work ${ }^{(7)}$ the notion of a global mindset was connected to intercultural skill development and in particular to the concept of cultural intelligence (CQ). CQ is a four-factor concept which encapsulates a flexible personal capability that can be enhanced through multi-cultural experiences, travel, education, training and self-awareness programs. It is observable in the broad capacity to function effectively across a variety of cultural contexts that includes ethnicities, generations and organizations, and is seen as “... a malleable capability that can be enhanced by multi-cultural experiences, training and self-awareness programs, travel and education $^{(16)}$." Four CQ capabilities characterize the intercultural capacity of a person: (1) $C Q$ drive, which relates to a person's motivation, interest and confidence in settings with cultural diversity; (2) CQ knowledge, which refers to knowledge about how cultures are similar or different; (3) CQ strategy, which is how a person makes sense of culturally diverse experiences and social situations; and, (4) CQ action, which signifies a person's capability to adapt their verbal and non-verbal cultural behaviors to appropriately suit a particular context ${ }^{(17)}$.

Taking an educational perspective, the understanding is therefore that continued exposure to meaningful experiences that are foreign to our usual situations and expectations, invites and develops new responses to the diverse stimuli that unknown environments, languages, traditions and values provide, thus creating new learning $^{(7)}$. Given time and repetition of this learning, a flexibility of mind is developed which is central to the growth of CQ and the formation of a global mindset. Research therefore suggests that a global mindset can be nurtured through improving intercultural skills, or developing $\mathrm{CQ}^{(6)}$, and also within higher education practices $^{(1,18,19)}$.

\section{The Study}

To investigate the development of CQ in higher education, our project applies instructional design (ID) theory to the intercultural learning of Japanese undergraduates. We utilize an earlier developed framework that weaves together relevant theoretical models with experiential learning ${ }^{(13)}$ and, in further research applications ${ }^{(7-9,12,13)}$, employ a blended learning format to foster intercultural skill development. Earlier findings ${ }^{(10,11)}$ indicated quantifiable gains for various aspects of CQ development, although not statistically significant. Other indicators, however showed positive effects in terms of activated learning, engagement patterns, and strong measures on summative learning outcomes. The present investigation seeks to add to these findings by presenting some of the qualitative results.

The focus here is on learner response patterns, expressed in terms of cultural competence indicators, such as knowledge, strategies, attitudes and self-perceived intercultural skills that were recorded through a series of online formative assessments and feedback surveys. The qualitative analysis draw connections to the CQ concept via students' self-reported advances in cultural knowledge, skills and strategies, as well as changes in attitudes and beliefs. Course effectiveness and learning engagement are discussed in view of the larger project aims, which is concerned with the design of a learning management system that develops CQ and assists in the formation of a global mindset.

\subsection{Methods and Procedures}

\subsubsection{Design}

To activate the current approach, a blended learning format was employed within our previously developed framework ${ }^{(11)}$. This framework was designed to integrate three relevant fields: instructional design (ID), 
experiential learning and CQ theory. Earlier findings suggested a successful integration of the framework with a design sequence to support intercultural learning and CQ development ${ }^{(10,11)}$.

Training and structured learning are essential components in the development of intercultural skill ${ }^{(15)}$, and in line with our project goals ${ }^{(10,11)}$, is utilized in conjunction with educational technology to support the blended learning format. Blended learning is an increasingly popular form of instruction that has been shown to offer alternative possibilities to traditional ways of learning ${ }^{(20)}$. It is described as "a pedagogical approach that combines the effectiveness and socialization opportunities of the classroom with the technologically advanced possibilities of the online environment... ${ }^{(20)}$ (p. 3)." It therefore has the potential to bring together advantages of both worlds, with learners and instructors developing new roles in the learning process. This approach makes a positive impact on higher education since it contains the underpinnings of a transformative model which can alter the expectations and practice of all the learning participants: faculty, administrators and students ${ }^{(20)}$.

A further advantage of this format is that experience-based learning, which is central to our framework $^{(11)}$, can be prioritized at different times through a variable and focused instruction in a F2F classroom situation with an instructor as mediator ${ }^{(20)}$. The blended learning format utilized here thus incorporated three areas which are important to an ID application: (1) a focus on relevant learning content; (2) formative and summative assessment/evaluation; and (3) the generation of data for research and development purposes. Earlier research work $^{(9,10)}$ presented a comprehensive outline and discussion of the intercultural learning course contents, its rationale and methods of instruction, and we therefore provide only a brief summary here.

The design of our framework is cognizant of a research contention ${ }^{(3)}$ that intercultural training needs a pedagogy that can support the development of CQ. We therefore designed a basic frame that integrated ID principles, experiential learning and CQ theory ${ }^{(9,10)}$, aiming to ensure the effective dissemination of learning, track and evaluate the learning process itself and deliver research data for a learning analysis. To activate the framework, we developed a course to encourage intercultural learning, or CQ growth, in support of the formation of a global mindset. The course consists of three broad organizing elements: 1) learning content; 2)
Table 1. Course Design: Developing CQ through Blended Learning.

\begin{tabular}{cl}
\hline & - Textbook reading \\
& $\cdot$ Classroom worksheets (instructor designed) \\
Learning & - Mini-lectures (topical contents) \\
Content & Online media, surveys, feedback \\
& - International Virtual Exchange Project \\
& - Flipped method: reading/comprehension/ \\
& audio \\
\hline Assessment \& & $\cdot$ Online review quizzes (4) \\
Evaluation & $\cdot$ Online class feedback surveys (13) \\
\hline & $\cdot$ CQ Scale \\
Research & - Online surveys (weekly) \\
\hline
\end{tabular}

* Adapted from Roux et al. ${ }^{(10,11)}$

assessment and evaluation; and 3) research. Each of these domains are divided into segments, indicating the relevant learning considerations and rationale in relation to CQ development. Learning content included the following: (a) textbook studies; (b) classroom worksheets; (c) a series of mini-lectures; (d) experience-based classroom activities (in groups/pairs); (e) online media (videos, audio, readings, public lectures); (f) one multi-cultural workshop; (g) a Moodle-based international virtual exchange with students in a foreign setting; and (h) homework, based on a flipped model of instruction ${ }^{(9,10)}$. A broad overview of the course is provided in Table 1.

Drawing on our framework's embedded theories, we designed a 15-week course for a face-to-face (F2F) environment equipped with PC's and WiFi. The course included significant portions of synchronous and asynchronous activities that formed part of the formative and summative assessment, thus delivering research data.

\subsubsection{Participants}

Thirty undergraduates (2nd and 3rd year) participated in the 15 -week course. The course typically prepares students for a short- and/or long-term study abroad experience, but often include students who maintain an active interest in developing their English literacy. The gender balance was $63 \%$ female and $37 \%$ male and except for one Taiwanese student, all participants were Japanese. The majority of the group (64\%) reported limited to moderate prior intercultural experience. 


\subsubsection{Procedures}

Face-to-face weekly lessons took place in a classroom with desktop PC's and WiFi. Students had the choice of using smart devices and/or PC's. Instructional methods included variations of facilitated group- and/or pair work, engaging with online media and lectures. A further component included an online, asynchronous exchange with a group of Colombian college students. Weekly learning reflections designed to track course engagement were recorded online through Google forms. These learning reflections included a 'free comments' section that was designed to gather non-structured learner feedback, on the premise that it would invite unsolicited learning observations and self-reflections that could link to the goals of our investigation. These form the basis of the learning analysis that is the focus of the current paper.

Forthwith, we present an analysis (conducted with NViVO software tools) of the qualitative feedback gleaned from the 'free comment' sections of the formative assessments. We reasoned that this reflective type of feedback could be suggestive of changes in learners' notions of self-perceived intercultural skill development and thus potentially compatible with increases in CQ, which could provide additional support for our broader investigation. The analysis further traces learning responses in search of thematic patterns that would link with CQ and the concomitant formation of a global mindset.

\subsection{Results}

To investigate the self-perceived intercultural skills of participants, we initially performed a word-frequency analysis as a starting point for understanding the free comment section of the online feedback forms. Table 2 below provides these results, showing the top 50 words and their relative strength of occurrence, given as a weighted percentage.

From this data, we used the top 14 frequently occurring words (weighted average percentage larger than $1 \%$ ) to achieve a closer approximation of potential keywords that could indicate potential avenues for further analysis. These frequently occurring words, which includes references to 'class,' 'think, ' 'conflict,' 'learn' and 'want,' 'difficult,' among the most common are graphically displayed in Figure 1 below.
From these frequency occurrences we constructed a word-cloud depicted in Figure 2. This depiction also gives an indication of the relative emphasis given to course contents in the feedback, as well as providing a sense of the relative strength of occurrence of these words. At this descriptive level of the analysis, the results only provide limited insights in reference to the actual content of the feedback; however, it does give a reflection of some of the keywords that might be important to consider when looking for potentially emergent themes in the data.

It is important to note that these frequencies provide only a preliminary indication for possible trends in the data. Given the relatively low amount $(33$, or $14 \%)$ of instances that were coded here as self-perceived developments, we are reluctant to attach significant value to these results at this stage. Instead, we treat them as indicators for exploring course feedback as indicators of potentially meaningful themes for further exploration at a later stage, perhaps with a larger dataset.

In addition, and to explore potentially emerging themes from the feedback, we developed and utilized a coding system supported by NViVO software that resulted in an arrangement with several categories. Categories that emerged from the comments were themed as follows: (a) learning observations; (b) learning motivation; (c) cultural knowledge; (d) self-perceived intercultural skills; (e) perceptions and attitudes; (f) international virtual exchange; (g) others; and (h) nil (no response given). These categories are depicted in Figure 3 below.

In line with our present purpose, we focused further analysis on the (highlighted) category of self-perceived intercultural skills. Analysis of this category indicate 33 instances of these types of freely volunteered responses ( $14 \%$ of the total 244 coded comments) from the four online reviews $(N=30)$. Although this is a relatively small number, it should be kept in mind that it is a small participant group and that we are particularly interested in qualitative feedback that could indicate (to some degree) how learners self-reflected on their own $\mathrm{CQ}$ development. The relatively small number of instances therefore represents only a very limited data set for analysis, which mitigates against employing a quantitative statistical analysis.

Within this category, five broad themes emerged and revealed links that could be tied to our identified purpose: (1) personal values and beliefs; (2) cultural 
Table 2. Word Count and Weighted Percentage.

\begin{tabular}{|c|c|c|}
\hline Word & Count & Weighted percentage \\
\hline culture & 45 & $4.61 \%$ \\
\hline class & 28 & $2.87 \%$ \\
\hline think & 28 & $2.87 \%$ \\
\hline conflict & 22 & $2.25 \%$ \\
\hline learn & 22 & $2.25 \%$ \\
\hline want & 22 & $2.25 \%$ \\
\hline difficult & 20 & $2.05 \%$ \\
\hline people & 19 & $1.94 \%$ \\
\hline know & 18 & $1.84 \%$ \\
\hline interesting & 14 & $1.43 \%$ \\
\hline thank & 13 & $1.33 \%$ \\
\hline understand & 13 & $1.33 \%$ \\
\hline conflicts & 12 & $1.23 \%$ \\
\hline cultural & 11 & $1.13 \%$ \\
\hline good & 11 & $1.13 \%$ \\
\hline learned & 9 & $0.92 \%$ \\
\hline many & 9 & $0.92 \%$ \\
\hline chapter & 8 & $0.82 \%$ \\
\hline hidden & 8 & $0.82 \%$ \\
\hline knowledge & 8 & $0.82 \%$ \\
\hline nothing & 8 & $0.82 \%$ \\
\hline project & 8 & $0.82 \%$ \\
\hline study & 8 & $0.82 \%$ \\
\hline things & 8 & $0.82 \%$ \\
\hline deeply & 7 & $0.72 \%$ \\
\hline different & 7 & $0.72 \%$ \\
\hline I've & 7 & $0.72 \%$ \\
\hline like & 7 & $0.72 \%$ \\
\hline time & 7 & $0.72 \%$ \\
\hline values & 7 & $0.72 \%$ \\
\hline communicate & 6 & $0.61 \%$ \\
\hline countries & 6 & $0.61 \%$ \\
\hline however & 6 & $0.61 \%$ \\
\hline important & 6 & $0.61 \%$ \\
\hline Japanese & 6 & $0.61 \%$ \\
\hline really & 6 & $0.61 \%$ \\
\hline change & 5 & $0.51 \%$ \\
\hline chapters & 5 & $0.51 \%$ \\
\hline enjoy & 5 & $0.51 \%$ \\
\hline foreign & 5 & $0.51 \%$ \\
\hline fun & 5 & $0.51 \%$ \\
\hline get & 5 & $0.51 \%$ \\
\hline lot & 5 & $0.51 \%$ \\
\hline much & 5 & $0.51 \%$ \\
\hline new & 5 & $0.51 \%$ \\
\hline nil & 5 & $0.51 \%$ \\
\hline thought & 5 & $0.51 \%$ \\
\hline use & 5 & $0.51 \%$ \\
\hline value & 5 & $0.51 \%$ \\
\hline way & 5 & $0.51 \%$ \\
\hline
\end{tabular}

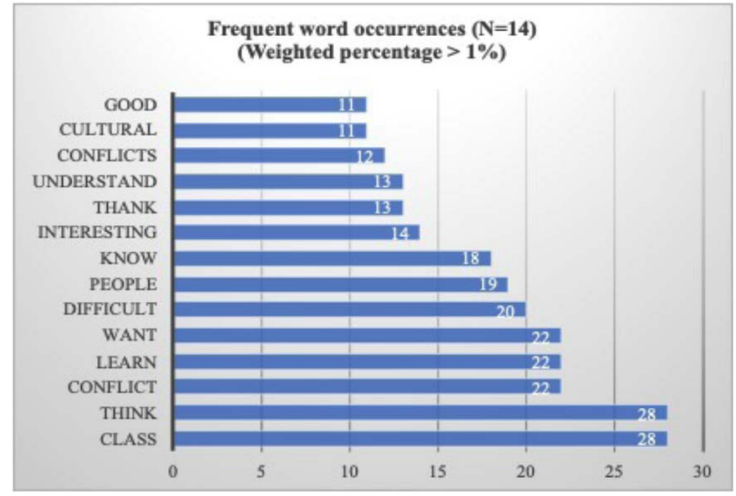

Figure 1. 'Free Comments': Word Frequency.

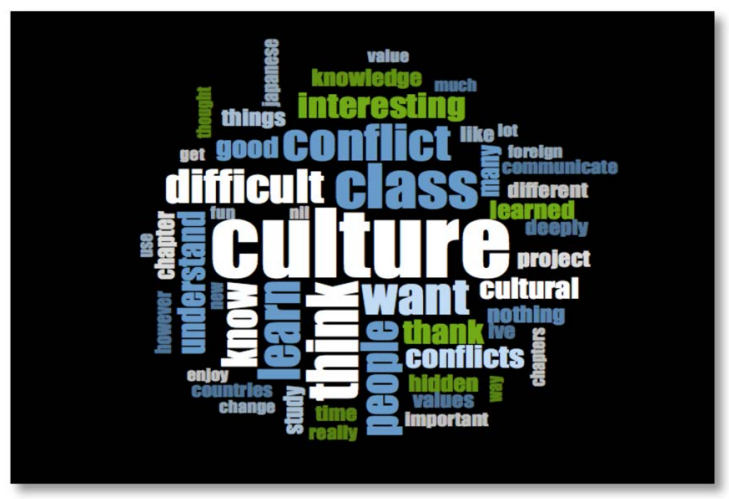

Figure 2. 'Free Comments': Word Cloud.

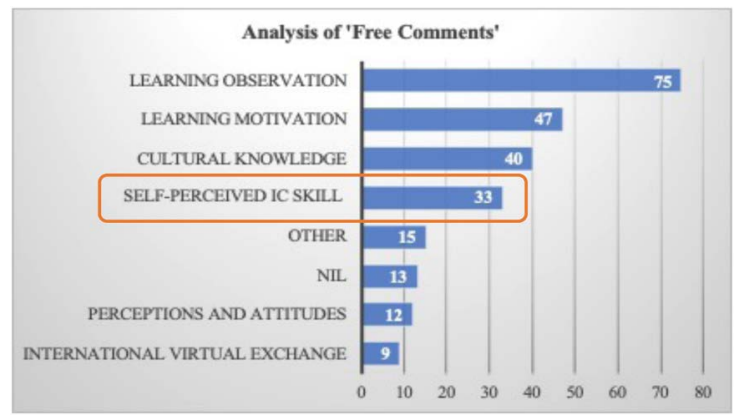

Figure 3. 'Free Comment' Analysis. 
Table 3. Self-Perceived CQ Development Samples.

\begin{tabular}{|c|c|}
\hline Theme & Sample \\
\hline $\begin{array}{c}(1) \\
\text { Values \& beliefs }\end{array}$ & $\begin{array}{l}\text { I was interested in ranking of values. } \\
\text { When I compare my answer with my } \\
\text { partner, I found differences about rank- } \\
\text { ing. I could notice about each person } \\
\text { has own values and opinions }\end{array}$ \\
\hline $\begin{array}{c}(2) \\
\text { Cultural } \\
\text { knowledge }\end{array}$ & $\begin{array}{l}\text { I think I learned a lot of new things } \\
\text { about culture. I like to communicate with } \\
\text { many people, not only Japanese but also } \\
\text { people from other countries, but it is } \\
\text { needed to understand there are cultural } \\
\text { difference between I and others. This } \\
\text { class is really effective for me to study } \\
\text { about it. }\end{array}$ \\
\hline $\begin{array}{c}\text { (3) } \\
\text { Cross-cultural } \\
\text { communication }\end{array}$ & $\begin{array}{l}\text { I assumed I can communicate with for- } \\
\text { eign people just by learning and speak- } \\
\text { ing English, but I realized I should learn } \\
\text { not only English but also history through } \\
\text { this class, especially watching TED. }\end{array}$ \\
\hline $\begin{array}{c}\text { (4) } \\
\text { Personal behavior }\end{array}$ & $\begin{array}{l}\text { I want more people to know why conflicts } \\
\text { happen by stereotypes and perception } \\
\text { and how we do to resolve conflicts we } \\
\text { are facing. And I thought I will try the } \\
\text { way I learned. }\end{array}$ \\
\hline $\begin{array}{c}(5) \\
\text { Conflict }\end{array}$ & $\begin{array}{l}\text { Before this lecture, I think culture } \\
\text { depend on each country or community. } \\
\text { But now I think culture have more deep } \\
\text { meaning. For example, visible culture, } \\
\text { hidden culture and cultural roots. Visible } \\
\text { culture can change easily, however hid- } \\
\text { den culture is difficult to change. Hidden } \\
\text { culture and cultural roots are difficult to } \\
\text { understand, so sometimes cause conflict. } \\
\text { I understood why conflicts happen } \\
\text { between communities }\end{array}$ \\
\hline
\end{tabular}

knowledge; (3) cross-cultural communication; (4) personal behavior (self and others); and (5) cultural conflicts. Together, these results were taken as potential indicators of self-perceived intercultural skill developments. To demonstrate how these results link to the current investigation, that is, how CQ develop as a self-perceived skill, we provide a sample (Table 3) from the reflection feedback section. The contents of these learner comments should demonstrate how participants considered their learning and engagement with the course.

\section{Findings and Discussion}

(a) Feedback shows at least five emergent themes related to self-perceived intercultural skill developments. These themes were categorized and formulated as standing in relation to: (1) personal values and beliefs; (2) cultural knowledge; (3) cross-cultural communication; (4) personal behaviour (self and others); and (5) cultural conflicts. In terms of our current investigation, which sought to explore and examine learner engagement in relation to the course goals, we could find fairly good indications that learners' self-perceived skills are in fact related to the intercultural issues that the course aimed to teach. This finding, even though limited in terms of its size, complement earlier findings in our project ${ }^{(9,10)}$, providing further support for our original framework and the goals of the current course.

(b) The identified themes stood in direct relation to the learning contents and further connected well with the four-factor model of the CQ concept. The results show that there was an impact on learners' personal perceptions, values and beliefs, which corresponds to the CQ meta-cognition dimension. In addition, learners reported an expansion of cultural knowledge and a realization of new understandings, which speaks to the CQ knowledge dimension. Other reported gains relate to increases in cross-cultural communication and interpersonal skills that connects with the CQ behaviour dimension. Finally, learner comments reflected a deepened realization and understanding in their cultural learning, with reference to their own thinking and future behaviour, suggesting that the CQ motivation dimension was impacted upon. These results also extend findings reported elsewhere ${ }^{(13)}$, which support the current instructional system's learning outcomes.

(c) It is important to note however that these results represent emergent themes that not only overlap with each other but should only be loosely tied to the CQ model at this stage. Although the current indications are positive, further work needs to be done to establish how these links can be sustainably made through the existent instructional design and methodology. Doing so would provide further support to the currently self-recorded instances of intercultural skill development, which we are linking to CQ increases.

(d) Finally, the present analysis represents only preliminary insights into the qualitative aspects of our project. Given our current purpose and the relatively 
small size of the participant group, we did not proceed with an additional quantitative analysis. We reported elsewhere ${ }^{(10,11)}$ on the quantitative gains specifically related to CQ measurement which the present investigation aimed to extend.

\section{Conclusion}

As part of a broader project to apply ID thinking to the development of $\mathrm{CQ}$, this study reported the qualitative results of a blended learning course. We reported an effort to trace learning engagement through the feedback/reflection of students' self-perceived intercultural skills development, which we link with the notion of CQ and the formation of a global mindset. Results from the analysis of feedback from two consecutive courses indicated that such a link seems very plausible, since the freely ventured student comments related directly to learners' self-perceived development of cultural intelligence indicators as described by the CQ model. These findings further provide a positive indication for the course engagement levels and learning outcomes. In terms of our framework that incorporated the CQ model, it is thus a very positive indication that ties into the success of the original design methodology.

As for the instructional method, it appears that the blended learning model proved an effective approach that tied well with our framework. Although current indications are positive, further work continues to explore how instructional design and methodology can support the development of CQ, and in particular, how these links can be sustainably made in course instruction. Given the theorized connection between CQ and the notion of a global mindset, the current employment of the blended learning approach holds promise for further investigations in this area. Examining learners' selfperceived notions of how their CQ is developing provide fascinating insights into the growth of cultural learning and intercultural skills development. The utility of a reflective method, supported here through online means, enabled a deeper understanding and given its success in delivering rich qualitative data, will continue to be explored in the future.

\section{References}

(1) Stoner, L., Perry, L., Page, R. et al.: "Fostering Global Citizenship in Higher Education", in Handbook of
Research on Study Abroad Programs and Outbound Mobility, eds. Velliaris, D. M. and Coleman-George, D., pp. 398-419. IGI Global, Hershey PA, USA (2016).

(2) Knight, J.: "Internationalization Remodeled: Definition, Approaches, and Rationales", J. of Studies in International Education, Vol. 8, No. 1, pp. 5-31 (2004).

(3) Fischer, R.: "Cross-Cultural Training Effects on Cultural Essentialism Beliefs and Cultural Intelligence", Int'1 J. of Intercultural Relations, Vol. 35, No. 6, pp. 767-775 (2011).

(4) Mori, J. and Takeuchi, J.: "Campus Diversity and Global Education: A Case Study of a Japanese Program”, Foreign Language Annals, Vol. 49, No.1, pp. 146-161 (2016).

(5) Japanese Ministry of Education, Culture, Sports, Science and Technology (MEXT). http://www.mext.go.jp/ (accessed 2018.12.2)

(6) Lovvorn, A. S. and Chen, J. S.: "Developing a Global Mindset: The Relationship between an International Assignment and Cultural Intelligence", Int'1 J. of Business and Social Sciences, Vol. 2, No. 9, pp. 275-283 (2011).

(7) Roux, P. W.: "Developing a Global Mindset: Designs for Blended Learning", J. of the Organization for General Education, Vol. 6, pp. 145-156 (2018).

(8) Roux, P. W., Suzuki, K., Matsuba, R. et al.: "Developing a Global Mindset in Higher Education: Designs for Blended Learning", Proc. of the Annual Student Conference of the Japanese Society for Information and Systems in Education (JSISE) Kyushu Branch, pp. 265266 (2017).

(9) Roux, P. W., Suzuki, K., Matsuba, R. et al.: "Instructional Design for Developing Cultural Intelligence (CQ): Lessons from Blended Learning", Proc. of the $15^{\text {th }}$ International Conference on Media in Education (ICoME), Japan Association for Educational Media Study (JAEMS) (2018).

(10) Roux, P. W., Suzuki, K., Matsuba, R. et al.: "Developing Cultural Intelligence (CQ): Designs for Blended Learning", Int'1 J. for Educational Media and Technology, (IJEMT), Vol. 12, No. 1, pp. 18-28 (2018).

(11) Roux, P. W. and Suzuki, K.: "Designing Online Instruction for Developing Cultural Intelligence (CQ): A Report from a Classroom-Based Workshop", Int'l J. for Educational Media and Technology (IJEMT), Vol. 11, No. 1, pp. 87-96 (2017).

(12) Roux, P. W. and Suzuki, K.: "Designing Online Instruction for developing Cultural Intelligence (CQ): Intercultural Journeys in a Blended Learning Environment", Proc. of the $14^{\text {th }}$ International Conference on Media in 
Education (ICoME), Japan Association for Educational Media Study (JAEMS), pp. 422-427 (2017).

(13) Roux, P. W., Suzuki, K., Matsuba, R. et al.: "Exploring Self-Perceived Development of Cultural Intelligence (CQ) in a Blended Learning Environment", Proc. of the Annual National Conference of the Japanese Society for Information and Systems in Education (JSISE), pp. 405406 (2018).

(14) Livermore, D.: The Cultural Intelligence Difference Special E-book Edition: Master the One Skill You Can't Do Without in Today's Global Economy, New York, AMACOM (2011).

(15) Kedia, B. L. and Mukherji, A.: "Global managers: Developing a Mindset for Global Competitiveness", J. World Business, Vol. 34, No. 3, pp. 230-251 (1999).

(16) Cultural Intelligence Center, https://culturalq.com/

(17) Ang, S., Van Dyne, L. and Rockstuhl, T.: "Cultural

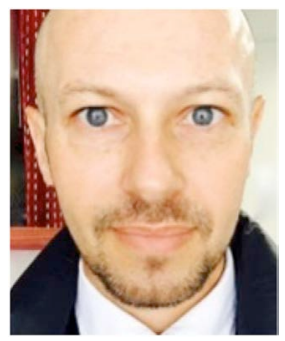

Peter W. Roux (Ph.D. Candidate) is a lecturer at the Organization for General Education, Faculty of Art and Regional Design at Saga University, Japan. He is an adjunct researcher at the Research Center for Instructional Systems (RCiS) at Kumamoto University, Japan. His research interests include the application of instructional design to intercultural learning, the psychology of learning, applied linguistics and how minds grow to benefit societies.

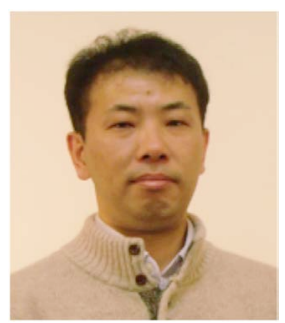

Ryuichi Matsuba (Ph.D.) is associate professor at the Research Center for Instructional Systems (RCiS) at Kumamoto University, Japan. His major field is online learning support in aspects both of technological and human. Recently, he is interested in how to effectively learn with e-portfolios.
Intelligence: Origins, Conceptualization, Evolution, and Methodological Diversity", in Handbook of Advances in Culture and Psychology, ed. Gelfand, M. J., Chiu, C. and Hong, Y., pp. 273-322. Oxford University Press, Oxford (2012).

(18) Tawil, S.: "Education for Global Citizenship: A Framework for Discussion", in Education Research and Foresight: Working Papers. United Nations Educational, Scientific and Cultural Organization (UNESCO) (2013).

(19) Hanson, L.: "Global Citizenship, Global Health, and the Internationalization of Curriculum: A Study of Transformative Potential", J. of Studies in International Education, Vol. 14, No. 1, pp. 70-88 (2010).

(20) Dziuban, C. D., Hartman, J. L. and Moskal, P.: "Blended Learning", Research Bulletin Educause Center for Applied Research (ECAR) (2004).

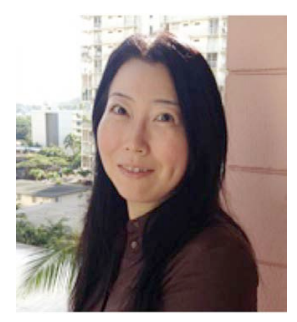

Yoshiko Goda (Ph.D.) is currently an associate professor in the Research Center for Instructional Systems (RCiS), Kumamoto University, Japan. She has been a director of the International Board of Standards for Training, Performance, and Instruction (ibstpi) since 2015. She received her $\mathrm{Ph} . \mathrm{D}$. from the Florida Institute of Technology in 2004 with the partial support of a Fulbright Scholarship. Her current research interests include self-regulated e-learning, instructional and learning design, online education program evaluation, technology enhanced language learning, and innovative communities for global education.

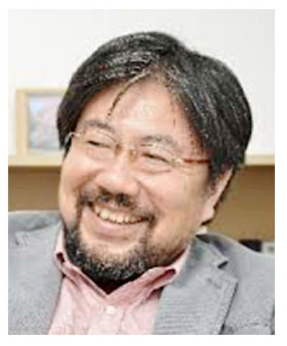

Katsuaki Suzuki (Ph.D.) is professor and chair at the Graduate School of Instructional Systems (GSIS), Kumamoto University, Japan. His ongoing research interests are instructional design theories and models, curriculum design for e-learning professional development, and instructional design and technology for international cooperation. 